\title{
A Novel Dielectric Slab Antenna Based on Microstrip-Franklin Excitation for mm-Waves
}

\author{
E. C. Vilas Boas (), A. A. C. Alves (), J. A. J. Ribeiro (1) and Arismar Cerqueira S. Jr. \\ Lab. Woca (Wireless and Optical Convergent Access), National Institute of Telecommunication (Inatel), Santa \\ Rita do Sapucaí - MG, Brazil \\ evandro.cesar@inatel.br,andreia.alves@mtel.inatel.br, justino@inatel.br,arismar@inatel.br
}

\begin{abstract}
This work reports the development of a novel dielectric slab antenna based on microstrip-Franklin radiators, which enables efficient impedance matching among microstrip lines, substrate and air. The proposed antenna has been designed and numerically evaluated using ANSYS HFSS ${ }^{\circledR}$. Its directivity ranges from 6.67 to $16.24 \mathrm{~dB}$, as its length is increased from 19.9 to $170 \mathrm{~mm}$. The $80 \mathrm{~mm}$ length antenna prototype provides $11.14 \%$ fractional bandwidth $(27.96$ - $31.26 \mathrm{GHz})$ and $10.5 \mathrm{dBi}$ gain at $30 \mathrm{GHz}$. The proposed antenna has been manufactured and applied to an indoor digital wireless communication link to provide $6 \mathrm{~Gb} / \mathrm{s}$ throughput using 64QAM modulation format, aiming 5G applications.
\end{abstract}

Index Terms - 5G, antennas, dielectric slab antenna, microstrip-Franklin antenna and mm-waves.

\section{INTRODUCTION}

The fifth-generation (5G) mobile network might be applied to four different scenarios [1]-[5]: massive machine-type communications (mMTC); extreme mobile broadband (eMBB); ultra-reliable low latency (URLL) communications; long-range communications for remote area access. The mMTC applications (such as the Internet of things (IoT) and vehicular communications (V2X)) require massive device connections network management, with thousands of devices per sector. These applications relate to the users' high-mobility and demand compact, lightweight, and low power consumption transceivers. The mMTC will support services using different frequency bands, including the second frequency range (FR2) from 24.25 to $52.60 \mathrm{GHz}$ [6]. The millimeter waves (mm-waves) bandwidth provides high data rates, with limited transmission range due to high free space losses [7]. Thereafter, mMTC antenna requirements have no longer been confined to low profile, but are also rather the high-performance characteristics, such as high gain.

Printed antennas have been applied in microwave frequencies, due to their advantages, such as low cost, low profile, and easy integration with printed circuits board (PCB). However, these radiators typically provide low directivity, then arrays are required in mm-waves applications, which increase the design complexity. Researchers worldwide have proposed several techniques as an attempt to enhance the printed antenna gain without using array [8]-[11]. Adding a superstrate of high permittivity above the planar antenna at a certain distance has been proved as an effective method to enhance the 
patch antenna gain [8]. Some authors proposed dielectric materials with air layers to obtain a high gain antenna [9]. The air gap reduces both the electric field concentration and effective dielectric constant of the radiating set. The parasitic patches technique relies on rectangular-shaped parasitic radiators on the antenna top [10]. Han et al. have proposed to enhance the gain and reduce the radar cross-section of a patch antenna by using a metamaterial surface [11]. These procedures require either material with different electrical properties or structures with specific design, increasing costs, volume, and complexity.

This work presents a new antenna based on microstrip-Franklin radiators $[12,13]$ and a dielectric slab devoted to $5 \mathrm{G} \mathrm{mm}$-waves communications. This radiator is low-profile, easily manufacturing, and high-performance in terms of bandwidth and gain. Conventional dielectric rod antennas (DRA) comprise a waveguide/coax transition and a dielectric rod, whose length influences the antenna directivity (Fig. 1(a)) [14]-[16]. These structures are bulky and difficult to integrate with PCBs. Our novel DRA (Fig. 1(b)) relies on applying a coupler to the full-wave structure for radiating electromagnetic waves and exciting surface and standing waves.

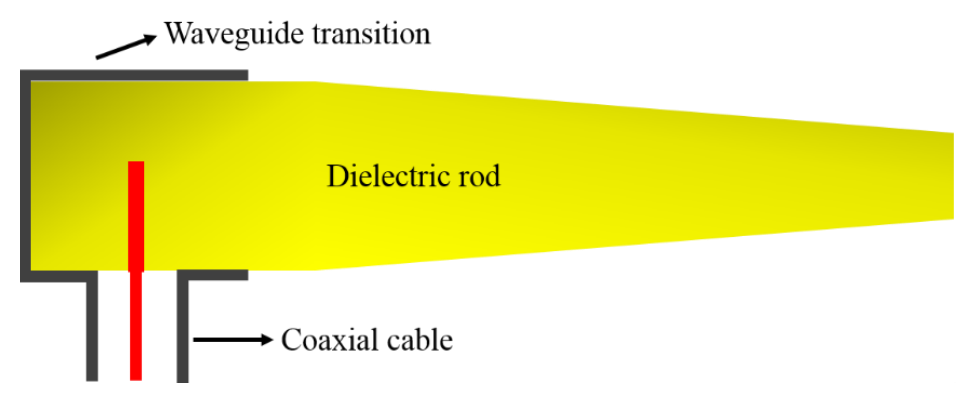

(a)

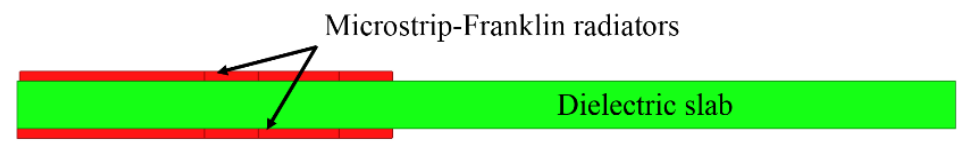

(b)

Fig. 1. Dielectric antenna side view (a) conventional structure and (b) the proposed design.

Related works have considered replacing the conventional DRA coupler by an RF connector. Substrate integrated waveguide (SIW), log-periodic dipole array, Yagi-Uda array and Vivaldi antennas have been used as primary feeding structures integrated with or into a bulky dielectric rod to enhance directivity. Meanwhile, our approach comprises a unique and simple feeder design. For instance, a dielectric-loaded SIW sectorial horn antenna has been designed for mm-waves operation [17]. Different dielectric loading shapes were integrated to the SIW structure, and its gain has been investigated as a function of the dielectric slab length. Additionally, a wideband DRA has been proposed comprising an SIW feeder, antipodal Vivaldi antenna, and a dielectric rod [18]. The antipodal Vivaldi antenna was used as a transition between the other structures. The dielectric rod has been placed at the end of the 
substrate. In another example, an antipodal Vivaldi antenna surrounded by a dielectric, for wideband applications such as microwave and mm-wave imaging, has been reported [19]. The antenna was designed on a dielectric substrate with an extended lens and integrated into a dielectric rod. Some authors developed a Yagi-Uda antenna array, also surrounded by a dielectric rod, to enhance gain and a circular reflector with low sidelobe levels [20]. The final structure is similar to a conventional DRA due to the reflector and its dielectric rod shape. Recently, a printed log-periodic dipole array has been used as a feeder to a DRA in [21]. The proposed design used the log-periodic dipole array as an adapter between the SIW and the dielectric rod, which is similar to that reported in [18].

Table I summarizes the state-of-the-art on dielectric antennas [17]-[21] based on fhe following metrics: the feeding structure type; the dielectric extension geometry; the prototype total length, as a function of the free-space wavelength at the central frequency $\left(\lambda_{c}\right)$; the feeding structure gain; the gain increase versus length. The previous works rely on complicated structures, including substrate integrated waveguide (SIW) [17], [18], Vivaldi antennas with lens [19] and Yagi-Uda [20] and logperiodic [21] antennas. On the other hand, our antenna is very simple and easy either for design and fabrication. Our antenna relies on using microstrip lie meandering-pattern, which is based on simple mathematical analysis equation, in contrast to the other dielectric antennas from Table 1, which typically use complex design methodology. This advantage optimizes the tuning process, since it reduces the number of design variables.

From a dielectric extension geometry point of view, the antennas exploited in [18], [20], [21] have kept the conventional dielectric rod, which results in a bulky structure, making their integration to PCBs difficult. The antennas proposed by Moosazadeh et al [19] and Nasir et al. [20] are integrated into a bulky dielectric, whereas our radiator, as well as that from [17], allows a rectangular dielectric extension. This characteristic corroborates to the easy fabrication and integration with PCBs. The authors from [19], [20] have reported $12 \mathrm{dBi}$ primary feeding structures gain. The first radiator integrates an Antipodal Vivaldi antenna with an extended lens to enhance its gain, while authors from [20] reported an Yagi-Uda antenna array with 20 elements.

Apart from [17], all other publications mentioned in Table I are for microwave frequency range. The Wang et al. proposed a high-gain SIW $H$-plane horn antenna with dielectric slabs for mm-waves [17], as well as in our case. Particularly, we have innovated due to the use of microstrip-Franklin excitation beyond broadside antenna design. To the best of our knowledge, our novel approach enabled to develop the first end-fire antenna array based on a microstrip-Franklin radiator.

The paper is structured in five sections. Section II is regarding the proposed antenna design and fabrication. The numerical and experimental results in terms of reflection coefficient, radiation pattern and gain are presented in Section III. Additionally, it is investigated the relationship between the substrate length and the antenna directivity. Section IV reports the experimental performance analysis in an indoor communication link based on a 64-QAM signal at $6 \mathrm{~Gb} / \mathrm{s}$ throughput. Conclusions and final comments are outlined in Section V. 
DOI: http://dx.doi.org/10.1590/2179-10742020v19i2822

TABLE I. COMPARISON AMONG THE PROPOSED DIELECTRIC SLAB ANTENNA WITH OTHER DIELECTRIC ANTENNAS.

\begin{tabular}{|c|c|c|c|c|c|}
\hline Reference & $\begin{array}{c}\text { Feeding structure } \\
\text { type }\end{array}$ & $\begin{array}{l}\text { Dieletric } \\
\text { extension } \\
\text { geometry }\end{array}$ & $\begin{array}{l}\text { Prototype } \\
\text { total length }\end{array}$ & $\begin{array}{c}\text { Feeding structure } \\
\text { gain }[\mathrm{dBi}]\end{array}$ & $\begin{array}{c}\text { Prototype dielectric } \\
\text { increased gain }[\mathrm{dB}] \text { vs. } \\
\text { length }\end{array}$ \\
\hline [17] & $\begin{array}{c}\text { Substrate } \\
\text { integrated } \\
\text { waveguide } H \text { - } \\
\text { plane horn } \\
\text { antenna (SIW) }\end{array}$ & Rectangular slab & $2.67 \lambda_{c}$ & 5.75 & $3.55-0.87 \lambda_{c}$ \\
\hline [18] & $\begin{array}{c}\text { Substrate } \\
\text { integrated } \\
\text { waveguide } \\
\text { Vivaldi antenna }\end{array}$ & Cylindrical rod & $0.65 \lambda_{c}$ & 2.30 & $2.23-0.14 \lambda_{c}$ \\
\hline [19] & $\begin{array}{c}\text { Antipodal } \\
\text { Vivaldi Antenna } \\
\text { with an extended } \\
\text { lens }\end{array}$ & Rectangular slab & $9.63 \lambda_{c}$ & 12.00 & $8.00-9.31 \lambda_{c}$ \\
\hline [20] & $\begin{array}{c}\text { Yagi-Uda } \\
\text { antenna array }\end{array}$ & $\begin{array}{l}\text { Cylindrical } \\
\text { tapered rod }\end{array}$ & $7.60 \lambda_{c}$ & 12.55 & $5.45-7.60 \lambda_{c}$ \\
\hline [21] & $\begin{array}{l}\text { Log-periodic } \\
\text { dipole array }\end{array}$ & $\begin{array}{l}\text { Cylindrical rod } \\
\text { with air holes }\end{array}$ & $8.80 \lambda_{c}$ & 7.00 & $5.5-2.0 \lambda_{c}$ \\
\hline $\begin{array}{l}\text { This } \\
\text { work }\end{array}$ & $\begin{array}{l}\text { Microstrip- } \\
\text { Franklin }\end{array}$ & Rectangular slab & $7.89 \lambda_{c}$ & 6.67 & $3.83-6.71 \lambda_{c}$ \\
\hline
\end{tabular}

\section{ANTENNA DESIGN}

The electromagnetic field emission by a microstrip line presents a radiation pattern with several lobes due to the current distribution phase [13]. However, it is possible to obtain co-phase current distribution and constructive radiated fields interference in the maximum radiation direction by using halfwavelength $(\lambda / 2)$ microstrip line with equal length segments folded into quarter-wave stubs [12], [13]. The half-wavelength and quarter-wave stubs might have equal or distinct characteristic impedances, as well as different meandering patterns, according to the design approach [12], [13]. This kind of structure is a traveling wave radiator so-called microstrip-Franklin antenna. It is applied to large linear antenna arrays in mm-waves [12], [13], [22].

In this work, the microstrip-Franklin antenna concept is used to design a microstrip transition for enhancing the impedance matching among microstrip lines, substrate and air. We have chosen a meandering-based geometry, initially proposed by K Solbach is [13], because it is simpler than others proposed in the literature. Moreover, this structure is suitable for our mm-waves fabrication facilities for antenna prototyping. The coupler relies on two half-wavelength microstrip lines, connected by two 
quarter-wave phasing stubs. A $50 \Omega$ microstrip line section has been added to allow the connector welding. The antenna layout and constructive parameters are presented in Fig. 2, in which $L_{o}$ and $W_{o}$ are the $50 \Omega$ microstrip line length and width, respectively, $L$ is the radiator total length, $W$ is the halfwavelength microstrip line width, $L_{t}$ is the length of the stub, $W_{t}$ is its width, $W_{f}$ is the slot width between the stubs, $L_{g}$ and $W_{g}$ are the substrate length and width.

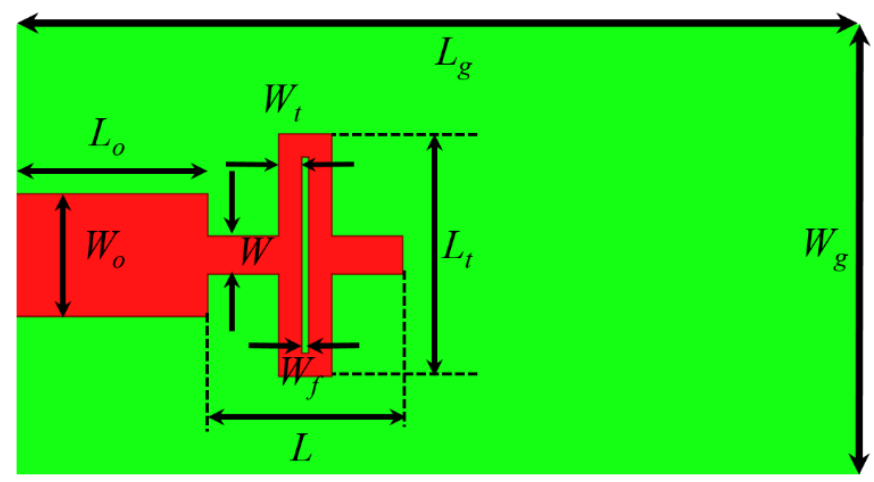

Fig. 2. The proposed antenna based on microstrip-Franklin radiators and dielectric slab.

The microstrip transition has been symmetrically printed onto the substrate opposite faces, as displayed in Fig 1(b). The antenna is excited by standard and surface waves along with dielectric structure, in such a way energy is gradually radiated. This phenomenon is similar to that observed in conventional DRAs with low permittivity dielectric materials (around $2 \varepsilon_{0}$ or $3 \varepsilon_{0}$ ) [12]. The stubs introduce an $180^{\circ}$-phase shift between the half-wavelength microstrip lines. Their geometry produces opposite current paths and cancels the stubs radiation. The symmetrical design between the stubs allows low parasitic discontinuity effects at the stubs and half-wavelength line junction [16]. The characteristic impedance $\left(Z_{o}\right)$ of the half-wavelength line and stubs were equals, and the value is obtained with

$$
Z_{o}=\sqrt{\frac{Z_{g} \eta_{o}}{\sqrt[4]{\varepsilon_{r}}}}
$$

in which $Z_{g}$ is the coaxial cable characteristic impedance, $\eta_{\mathrm{o}}$ is the air intrinsic impedance, and $\varepsilon_{r}$ is the substrate relative permittivity. Equation (1) was derived by taking a geometric mean among the microstrip line, air, and dielectric intrinsic impedances. First, a geometric mean is calculated between the air and dielectric intrinsic impedance, since the electromagnetic wave formed along the Franklin radiators propagates through these environments. Then, a second geometric mean is obtained between the first result and the microstrip line characteristic impedance.

\section{ANTENNA FABRICATION AND CHARACTERIZATION}

The antenna has been designed for $30 \mathrm{GHz}$, using an Arlon Diclad $880^{\circledR}$ substrate with $1.52 \mathrm{~mm}$ thickness, relative permittivity $\varepsilon_{r}=2.2$ and loss tangent $\tan (\delta)=0,0009$ at $10 \mathrm{GHz}$ [23]. The initial 
values of $W_{t}$ and $W$ have been calculated for a characteristic impedance of $124.4 \Omega$, by applying the substrate parameters in (1). The lengths $L_{o}, L_{t}$ and $L$ have been initially set equal to one half of the freespace wavelength and $W_{f}$ was obtained numerically. The antenna performance has been evaluated using the Finite Element Method (FEM) in ANSYS HFSS ${ }^{\circledR}$ [24]. Its final dimensions were: $L_{o}=6 \mathrm{~mm}$, $W_{o}=3.81 \mathrm{~mm}, L=6 \mathrm{~mm}, W=W_{t}=1.19 \mathrm{~mm}, L_{t}=7.48 \mathrm{~mm}, W_{f}=0.2 \mathrm{~mm}$ and $W_{g}=20 \mathrm{~mm}$. The values of $W_{t}$ and $W$ match with a characteristic impedance of $129.5 \Omega$, and represents an increase of approximately $4 \%$ from the predicted value. The antenna prototype with $80 \mathrm{~mm}$ substrate length (Fig. 3a) has been evaluated in terms of reflection coefficient, radiation pattern and gain. Fig. $3 \mathrm{~b}$ reports the simulated and measured reflection coefficient, whose bandwidths were $2.30 \mathrm{GHz}(28.96-$ $31.26 \mathrm{GHz})$ and $3.30 \mathrm{GHz}(27.96-31.26 \mathrm{GHz})$, respectively, defined through frequencies with reflection coefficient lower than $-10 \mathrm{~dB}$. Fig. $3 \mathrm{~b}$ corroborates the design.

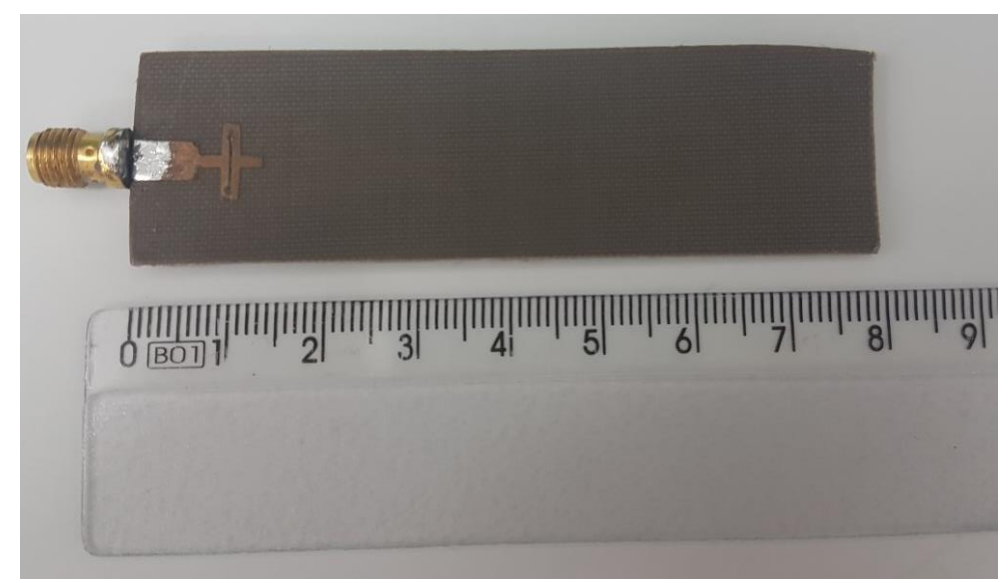

(a)

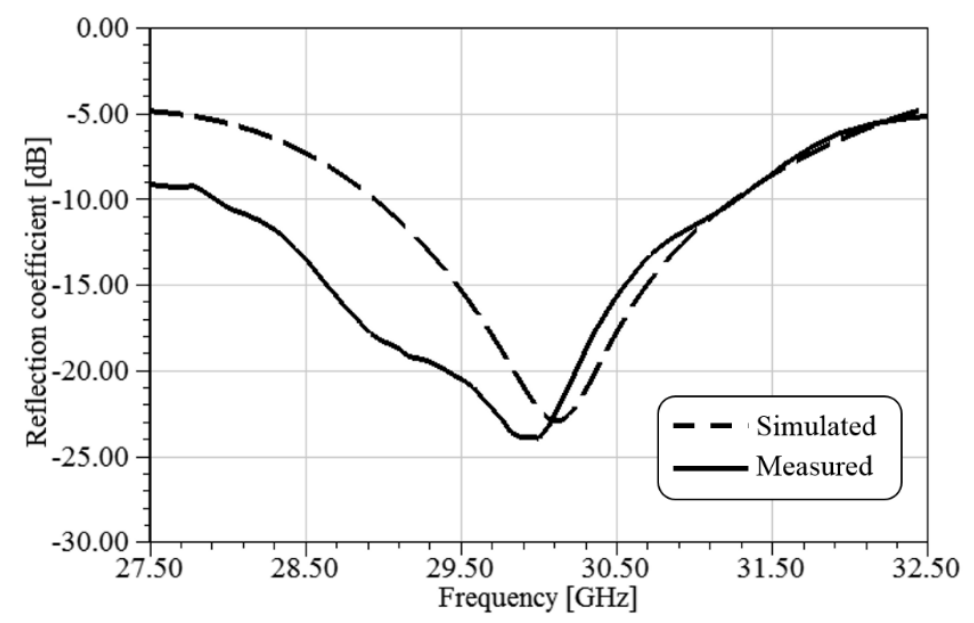

(b)

Fig. 3. Microstrip-Franklin excited dielectric slab antenna (a) prototype, (b) reflection coefficient.

The antenna directivity depends on the substrate length, since increasing $L_{g}$ allows higher gain levels, while its frequency response and radiator element are kept unchanged. Fig. 4a displays the numerical 
analysis of the antenna directivity at $30 \mathrm{GHz}$ as a function of the normalized substrate length $\left(\lambda_{e f}\right)$. It varies from 6.67 to $16.24 \mathrm{~dB}$, as the substrate length is increased from $19.9\left(\lambda_{e f}\right)$. to $170 \mathrm{~mm}\left(20 \lambda_{e f}\right)$. Fig. $4 \mathrm{~b}$ depicts the radiation pattern in the azimuth plane for three different substrate lengths, namely: $\lambda_{e f}, 10 \lambda_{e f}$ and $20 \lambda_{e f}$. The half-power beamwidth (HPBW) was for longer substrate lengths, which corroborates with the results from Fig. 4a.

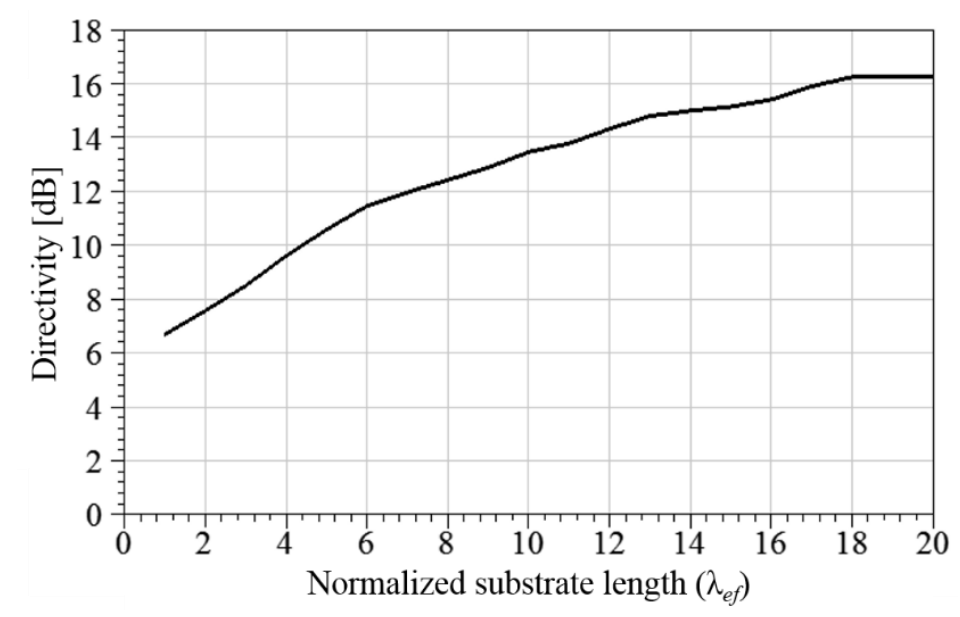

(a)

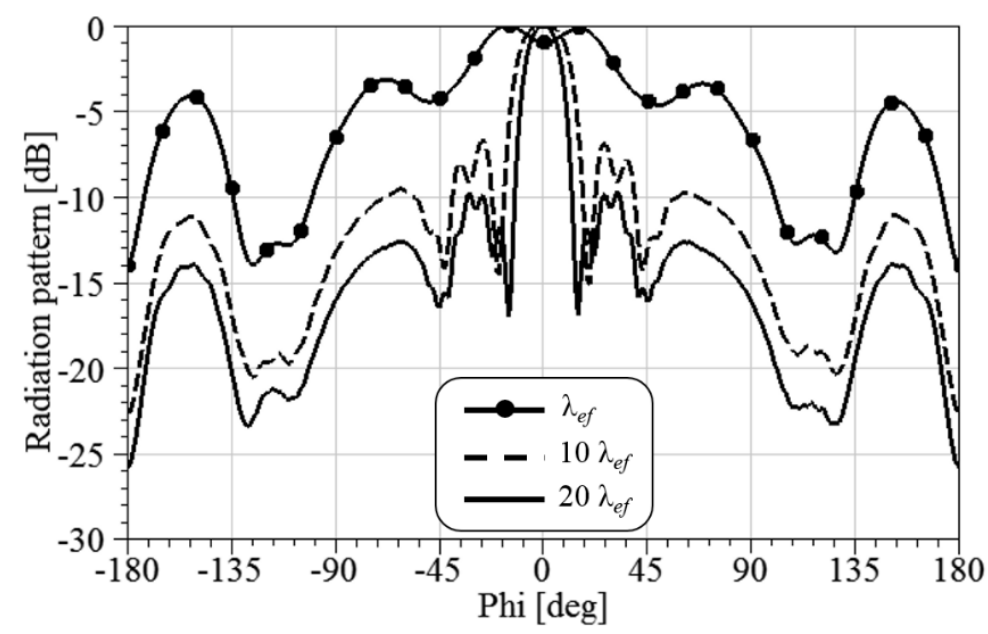

(b)

Fig. 4. Antena properties at $30 \mathrm{GHz}$ : (a) Directivity; (b) Azimuth radiation pattern $\left(\theta=90^{\circ}\right)$.

The radiation pattern and gain have been measured, using 25-dBi gain horn antennas as a reference, in an indoor environment at $30 \mathrm{GHz}$. The antennas were positioned $5 \mathrm{~m}$ away from each other and mounted at $2 \mathrm{~m}$ height. The simulated and measured normalized radiation pattern for the azimuth and elevation planes are depicted in Fig. 5 and have shown in the agreement. An asymmetric radiation pattern is observed in the elevation plane with higher side lobe levels between $20^{\circ}$ and $60^{\circ}$, when compared to the angular region from $120^{\circ}$ to $160^{\circ}$. This behavior was due to the feeding connector, 
whose dimensions are close to those of the proposed antenna. The measured gain was equal to $10.5 \mathrm{dBi}$ and HPBW in the azimuth and elevation planes were equal to $22.13^{\circ}$ e $25.81^{\circ}$, respectively.

Table II reports a performance comparison among the proposed dielectric slab antenna with previous works discussed in the Introduction Section. The following metrics have been comforted: fractional bandwidth (FBW), central frequency, gain and sidelobe level (SLL). The higher bandwidth radiators are those that the feeding structures are based on wideband antennas, such as Vivaldi [18], [19]. Similar to the FBW, the structure final gain is higher to those in which the fending structure employs an array or a enhancing-gain technique [19], [20]. Our dielectric slab antenna has the main advantages of simple design and fabrication, in conjunction with quite high gain -without using an array structure or lensand wide bandwidth. It provides lower SLL due to its RF connector dimensions, as discussed above. An essay without the RF connector has returned an SLL equal to $-12 \mathrm{~dB}$.

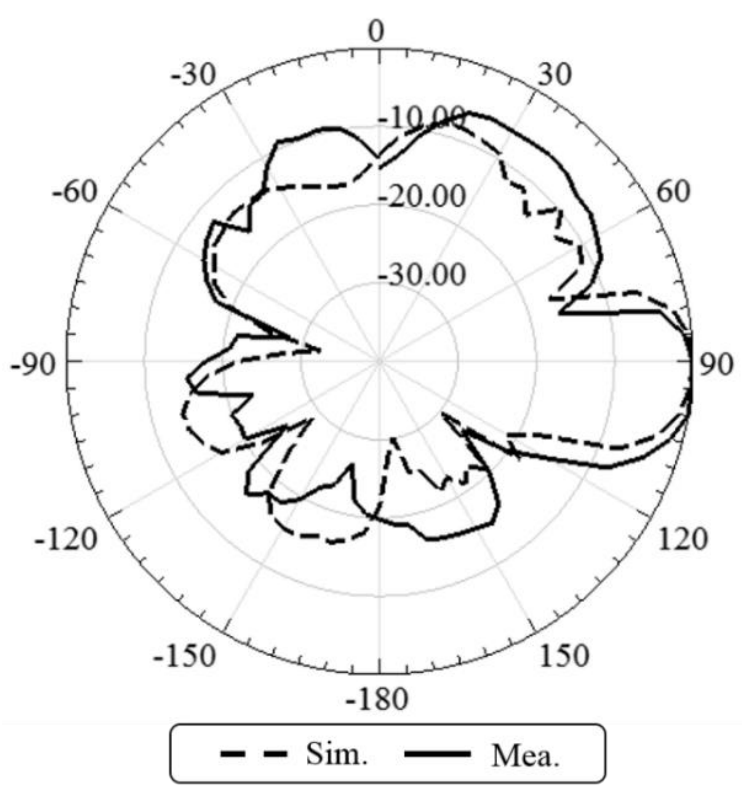

(a)

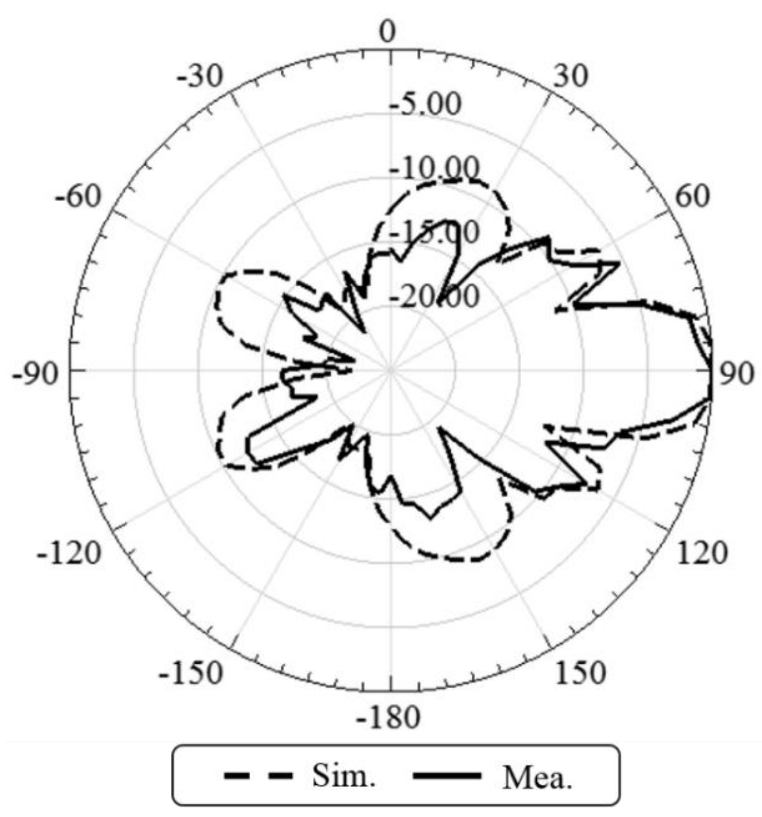

(b)

Fig. 5. Simulated and measured normalized radiation pattern at $30 \mathrm{GHz}$ : (a) Elevation plane; (b) Azimuth plane.

TABLE II. PERFORMANCE COMPARISON AMONG THE PROPOSED DIELECTRIC SLAB ANTENNA WITH OTHER DIELECTRIC ANTENNAS.

\begin{tabular}{ccccc}
\hline Reference & FBW [\%] & $f_{\mathrm{c}}[\mathrm{GHz}]$ & Gain [dBi] & SLL [dB] \\
\hline$[17]$ & 4.71 & 26.75 & 9.30 & $>10.00$ \\
{$[17]$} & 4.67 & 26.5 & 9.70 & $>8.27$ \\
{$[18]$} & 56.41 & 9.75 & 4.43 & $>5.00$ \\
{$[19]$} & 163.63 & 27.5 & 20.00 & $>14.60$ \\
{$[20]$} & 13.18 & 9.10 & 18.00 & $>23.37$ \\
{$[21]$} & 26.00 & 10.00 & 12.50 & - \\
This work & 11.14 & 29.61 & 10.50 & $>6.00$ \\
\hline
\end{tabular}




\section{INDOOR WIRELESS COMMUNICATION LINK IMPLEMENTATION}

This section reports the experimental results of the indoor wireless transmission using the proposed microstrip-Franklin dielectric slab antenna at $30 \mathrm{GHz}$. The setup block diagram is depicted in Fig. 6(a), whereas the experimental setup scenario photography is in Fig. 6(b). At the transmission side, a vector signal generator (VSG) provided a 64-QAM $6 \mathrm{~Gb} / \mathrm{s}$ signal, which was transmitted using a $25 \mathrm{dBi}$-gain horn antenna. The free-space loss, calculated by the Friis equation, was $79.96 \mathrm{~dB}$ for 5 meters length. Our antenna, followed by a $14 \mathrm{~dB}$-gain low noise amplifier (LNA), composed the received side. A vector signal analyzer (VSA) has been utilized to evaluate the RF received signal performance.

We have evaluated the system digital performance in term of the root mean square error vector magnitude $\left(\mathrm{EVM}_{\mathrm{RMS}}\right)$, as a function of the received power, as reported in Fig 7. The black curve with squares represents the back-to-back (B2B) condition, ensured by directly connecting VSG to VSA for comparison purposes. The red curve with circles represents the wireless transmission, in which the received power levels ranged from -38 to $-28 \mathrm{dBm}$. Digital pre-distortion (DPD) has been applied to enhance the system performance. DPD is a technique for compensating the channel fading in both phase and magnitude. The transmitter and receiver were connected using Ethernet protocol to establish

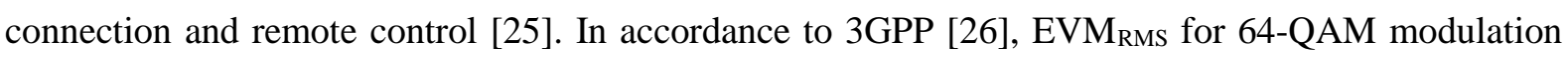
should not exceed $8 \%$. The proposed antenna allowed $\mathrm{EVM}_{\mathrm{RMS}}$ ranging from $5.75 \%$ and $7.73 \%$ for received power higher or equal than $-34 \mathrm{dBm}$, which fulfill the $3 \mathrm{GPP}$ requirement, illustrating its applicability to $5 \mathrm{G}$ systems.

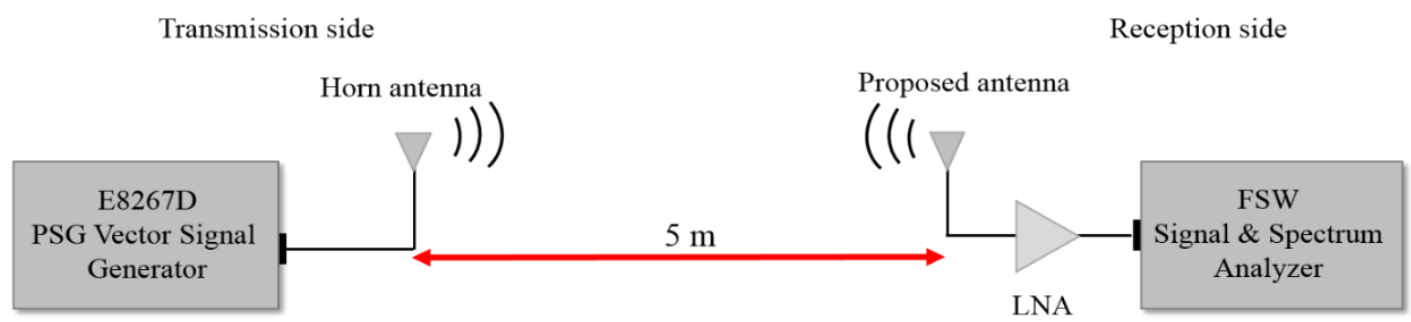

(a)

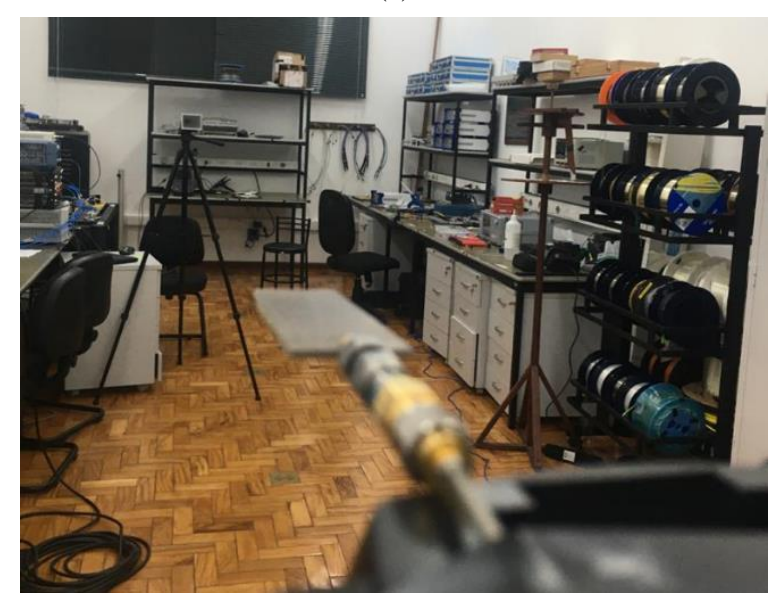

(b)

Fig. 6. Implementation of the dielectric slab antenna at $30 \mathrm{GHz}$ : (a) block diagram; (b) Experimental setup scenario photography. 


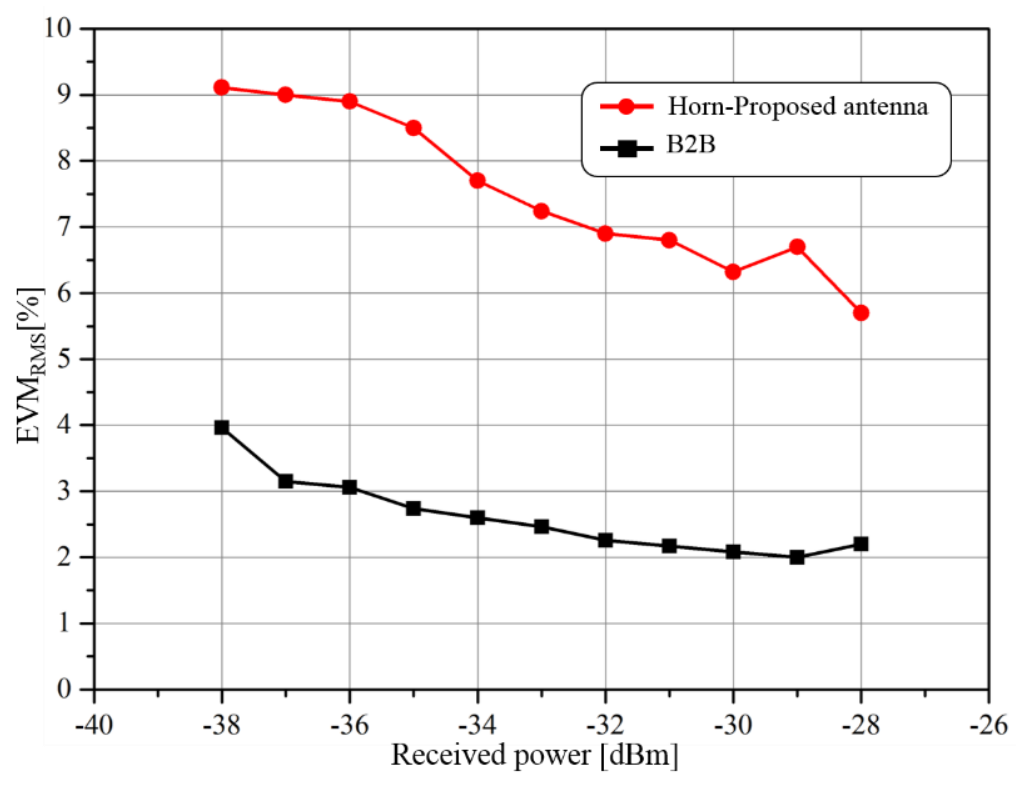

Fig. 7. Performance analysis as a function of EVMRMs: B2B (black curves with squares); wireless link using the proposed antenna (red curve with circles).

\section{CONCLUSIONS}

We have proposed, developed and applied a new and compact dielectric slab antenna, excited by microstrip-Franklin radiators for $5 \mathrm{G}$ mm-waves applications. The proposed design might be considered the first end-fire antenna array based on microstrip-Franklin radiators, which also comprise a novel technique to develop high-gain dielectric antennas, by means of extending its dielectric slab. Numerical simulation and experimental results have been shown in excellent agreement. The dielectric laminate length strongly influences the antenna directivity, allowing an enhancement of $9.57 \mathrm{~dB}$ (from 6.67 to $16.24 \mathrm{~dB}$ ), when it is increased from 19.9 to $170 \mathrm{~mm}$. A $80 \mathrm{~mm}$-length prototype provided measured bandwidth of $3.30 \mathrm{GHz}(27.96-31.26 \mathrm{GHz})$, half-power beamwidth equal to $22^{\circ}$ and $25^{\circ}$ in the azimuth and elevation planes, respectively, and $10.5 \mathrm{dBi}$ gain at $30 \mathrm{GHz}$. Finally, our antenna applicability has been successfully demonstrated, by its implementation in a $6 \mathrm{~Gb} / \mathrm{s}$ indoor wireless communication link. Future works regards the implementation of our compact dielectric slab antenna, excited by microstripFranklin radiators in a 5G outdoor environment, using our DSP-based flexible-waveform 5G Brazilian Transceiver [27].

\section{ACKNOWLEDGMENTS}

This work was partially supported by RNP, with resources from MCTIC, Grant No. No 01250.075413/2018-04, under the Radio communication Reference Center (Centro de Referência em Radiocomunicações-CRR) project of the National Institute of Telecommunications (Instituto Nacional de Telecomunicações-Inatel), Brazil, and Coordenação de Aperfeiçoamento de Pessoal de Nível Superior - Brasil (CAPES) - Finance Code 001. Authors also thank the financial support from CNPq, MCTI, FAPEMIG, and technical support from Keysight and ESSS-ANSYS. 


\section{REFERENCES}

[1] C. Bockelmann et al., "Towards Massive Connectivity Support for Scalable mMTC Communications in 5G Networks," in IEEE Access, vol. 6, pp. 28969-28992, 2018.

[2] P. Popovski et al., "5G Wireless Network Slicing for eMBB, URLLC, and mMTC: A Communication-Theoretic View," in IEEE Access, vol. 6, pp. 55765-55779, 2018.

[3] D. Soldani et al., "5G for Ultra-Reliable Low-Latency Communications," in IEEE Network, vol. 32, no. 2, pp. 6-7, MarchApril 2018.

[4] R. M. Borges et al., "Integration of a GFDM-Based 5G Transceiver in a GPON Using Radio Over Fiber Technology," in Journal of Lightwave Technology, vol. 36, no. 19, pp. 4468-4477, Oct.1, 2018.

[5] R. M. Borges et al., "Implementation of a Multi-Gbit/s and GFDM-based Optical-Wireless 5G Network," in Journal of Microwaves, Optoelectronics and Electromagnetic Applications, vol. 17, pp. 579-589, 2018.

[6] 3GPP TS 38.104 version 15.2.0 Release 15 [Online]. Disponível em:< https://www.etsi.org/deliver/etsi_ts/138100 _138199/138104/15.02.00_60/ts_138104v150200p.pdf >. Acesso em 15 de outubro.

[7] T. S. Rappaport et al., "Wideband Millimeter-Wave Propagation Measurements and Channel Models for Future Wireless Communication System Design," in IEEE Transactions on Communications, vol. 63, no. 9, pp. 3029-3056, Sept. 2015.

[8] D. Jackson and N. Alexopoulos, "Gain Enhancement Methods for Printed Circuit Antennas," in IEEE Transactions on Antennas and Propagation, vol. 33, no. 9, pp. 976-987, September 1985.

[9] S. S. Singh, S. R. Bhujade, "Design and Evaluation of High Gain Microstrip Patch Antenna using Double Layer with Air Gap," in International Journal on Recent and Innovation Trends in Computing and Communication, vol. 3, no. 3, pp. 1678-1681, 2015.

[10] B. Yildirim and B. A. Cetiner, "Enhanced Gain Patch Antenna with a Rectangular Loop Shaped Parasitic Radiator," in IEEE Antennas and Wireless Propagation Letters, vol. 7, pp. 229-232, 2008.

[11] Z. Han, W. Song and X. Sheng, "Gain Enhancement and RCS Reduction for Patch Antenna by using Polarizationdependent EBG Surface," in IEEE Antennas and Wireless Propagation Letters, vol. 16, pp. 1631-1634, 2017.

[12] S. Nishimura, K. Nakano and T. Makimoto, "Franklin-type Microstrip Line Antenna," in 1979 Antennas and Propagation Society International Symposium, vol. 17, pp. 134-137, 1979.

[13] K. Solbach, "Microstrip-Franklin Antenna," in IEEE Transactions on Antennas and Propagation, vol. 30, pp. 773-775, 1982.

[14] J. A. J. Ribeiro, Engenharia de Antenas: fundamentos, projetos e aplicações. $1^{\text {a }}$ ed. São Paulo, SP: Editora Érica, 2012.

[15] J. Chung e C. Chen, "Two-Layer Dielectric Rod Antenna," in IEEE Transactions on Antennas and Propagation, vol. 56, no. 6, pp. 1541-1547, June 2008.

[16] M. Sporer, R. Weigel e A. Koelpin, "A 24 GHz Dual-Polarized and Robust Dielectric Rod Antenna," in IEEE Transactions on Antennas and Propagation, vol. 65, no. 12, pp. 6952-6959, 2017.

[17] H. Wang et al., "Dielectric Loaded Substrate Integrated Waveguide (SIW) H-Plane Horn Antennas," in IEEE Transactions on Antennas and Propagation, vol. 58, no. 3, pp. 640-647, 2010.

[18] R. Kazemi, A. E. Fathy e R. A. Sadeghzadeh, "Dielectric Rod Antenna Array With Substrate Integrated Waveguide Planar Feed Network for Wideband Applications," in IEEE Transactions on Antennas and Propagation, vol. 60, no. 3, pp. 1312-1319, 2012.

[19] M. Moosazadeh, "High-Gain Antipodal Vivaldi Antenna Surrounded by Dielectric for Wideband Applications," in IEEE Transactions on Antennas and Propagation, vol. 66, no. 8, pp. 4349-4352, 2018.

[20] M. Nasir, Y. Xia, M. Jiang and Q. Zhu, "A Novel Integrated Yagi-Uda and Dielectric Rod Antenna With Low Sidelobe Level," in IEEE Transactions on Antennas and Propagation, vol. 67, no. 4, pp. 2751-2756, 2019.

[21] W. Jingxuan, et al. "Low-cost and Easy Manufactured Dielectric Rod Antennas based on 3D Printing Technology," In International Journal of RF and Microwave Computer-Aided Engineering, 2019.

[22] T. A. Milligan, Modern Antenna Design. $2^{\mathrm{a}}$ ed., New Jersey: John Wiley \& Sons, Inc., 2005.

[23] Rogers Corporation, datasheet DiClad® 870/880 Laminates. [Online]. Disponível em:< https://www.rogerscorp.com/acs/products/88/DiClad-870-880-Laminates.aspx>. Acesso em: 27 de outubro de 2016.

[24] ANSYS HFSS, http://www.ansys.com/Products/Electronics/ANSYS-HFSS.

[25] F. M. Ghannouchi,O. Hammi and M. Helaoui, Behavioral modeling and predistortion of wideband wireless transmitters. John Wiley \& Sons, 2015.

[26] 3GPP, Technical Specification Group Radio Access Network; NR; User Equipment (UE) radio transmission and reception; Part 1: Range 1 Standalone (Release 15), 3GPP TS 38.101-1 V15.5.0, 2019.

[27] R. M. Borges, L. A. M. Pereira, H.R.D. Filgueiras, A. C. Ferreira, M. S. B. Cunha, E. R. Neto, D. H. Spadoti, L. L. Mendes and Arismar Cerqueira S. Jr., "DSP-Based Flexible-Waveform and Multi-Application 5G Fiber-Wireless System," in Journal of Lightwave Technology, vol. 38, no. 3, pp. 642-653, 1 Feb.1, 2020. 